\title{
185
}

\section{HCV-RNA-PCR TEST QUANTITATIVO}

\author{
Spinosa M., Spagnuolo P. \\ Servizio di Immunoematologia e Centro Trasfusionale Day- \\ Hospital Onco-Ematologico Presidio Ospedaliero "San Timoteo" \\ Termoli (CB) A.S.L. n. 4 Basso-Molise Termoli-Larino.
}

Introduzione:L'introduzione dei test di Biologia Molecolare P.C.R. per la determinazione dell'HCV-RNA sono diventati uno strumento indispensabile per la diagnosi precoce riducendo il periodo finestra del virus HCV,per la valutazione dello stato di malattia e per la quantificazione della carica virale utile nel monitoraggio della terapia. Scopo del nostro lavoro è stato valutare il ruolo della quantificazione della carica virale in pazienti sottoposti a terapia.

Metodi:Sono stati valutati 289 pazienti HCV-RNA positivi. E' stata rilevata la viremia $\mathrm{HCV}$ quantitativa basale,alla $12^{\circ}$ settimana, alla $24^{\circ}$ settimana, alla $48^{\circ}$ settimana del trattamento. La ricerca dell'HCV-RNA è stata eseguita utilizzando Amplicor-HCV-Monitor (Roche).Per l'identificazione dei genotipi è stata utilizzata la metodica Lipa-HCV-Genotype (Bayer) applicata ai prodotti di amplificazione virale della regione 5'U.T.R.

Risultati: Dei 289 pazienti HCV-RNA positivi,dopo 12 settimane dal trattamento antivirale $85(29 \%)$ non hanno mostrato risposta virologica precoce. I restanti 204,33(11\%) hanno presentato risposta precoce ( $12^{\circ}$ settimana), $93(27 \%)$ una risposta alla $24^{\circ}$ settimana, $78(27 \%)$ una risposta alla $48^{\circ}$ settimana. La diversa risposta virologica alla terapia è correlata al tipo di genotipo che presentano una bassa sensibilità al trattamento (genotipo1e 4) rispetto al genotipo 2 e 3, e dai livelli di viremia.

Conclusioni: Da questi risultati si evince che lo studio della cinetica della viremia pre e durante la terapia ha permesso di identificare pazienti "non responder"e andamenti significativamente differenti in pazienti con risposta sostenuta rispetto

a quelli recidivati dopo sospensione della terapia. Questo ha permesso di valutare alcune condizioni:1)assenza dell'iniziale blocco della produzione virale,2)assenza della riduzione della viremia,3)insufficiente eliminazione delle cellule infette a fronte dell'effetto antivirale.Pertanto i test quantitativi permettono di valutare la probabile risposta prima di iniziare la terapia in relazione al genotipo,identificare i pazienti con risposta virologica precoce o con scarse o nulle probabilità di eradicazione dell'infezione a 12 settimane,identificare i "non responder" a 6 mesi dall'inizio della terapia e definire la risposta a fine trattamento e la risposta sostenuta. 